DOI: $10.29064 /$ ijma. 734734

\title{
ARTIFICIAL INTELLIGENCE ADOPTION AND EMPLOYEE PERFORMANCE IN THE NIGERIAN BANKING INDUSTRY
}

\author{
Ayobami F. ELEGUNDE ${ }^{1}$ \\ Reuben O. OSAGIE ${ }^{2}$
}

\begin{abstract}
The study examined Artificial Intelligence and Employee Performance in the Nigerian Banking Industry, Lagos Nigeria as a study to generalize results. The objective of this study was to examine the complementability of AI to work processes and to know if it eases employee operations in banks in Nigeria. Cross-sectional descriptive research design was adopted by the researcher. Primary data was to elicit information for this study. The population of the study was the entire employees of six (6) selected banks operating in Lagos State, Nigeria, which totaled 127 staff. The study adopted Taro Yamane (1967) sample size determinant to arrive at a sample size of 98 elements. 98 copies of questionnaires were administered to respondents of six banks in Lagos State, Nigeria, which was divided using simple proportion and ratio among the six banks, 98 respondents were used for data analysis. Content validity was adopted for this study. Reliability test was conducted using Cronbach Alpha and it returned 0.773 showing internal consistency of research instrument. Descriptive statistics such as mean, simple percentage was used to analyze the demography of respondents while regression and Pearson correlation coefficients were used to analyze data. The findings revealed that Artificial Intelligence complements work process in banks in Nigeria and that machine-aided tasks ease operations in banks in Nigeria. The study recommended the adoption of AI by not only banks but all other firms in the service industry; the need for all employees and people to be educated on the importance of embracing AI; the upgrading of school curriculum at all levels in developing and third world economies to incorporate $\mathrm{AI}$ and its accompanying gadgets.
\end{abstract}

Keywords: Artificial Intelligence, Complementability, Employee Performance, Ease of Operations

\footnotetext{
${ }^{1} \mathrm{PhD}$, Lecturer, ayobami207@gmail.com, Business Administration Department, Faculty of Management Sciences Lagos State University, Ojo, Lagos State, Nigeria.

${ }^{2}$ PhD Student, reubenosagie@ gmail.com, Business Administration Department, Faculty of Management Sciences Lagos State University, Ojo, Lagos State, Nigeria, ORCID: 0000-0003-3318-7433

(Correspondence)
} 


\subsection{Introduction}

In the early period of adoption of Artificial intelligence (AI) systems to work and work processes, in countries like Germany, USA, England, China, Japan, etc, emphasis of research and researchers alike was on its impact on the labour market (Decker, Fischer \& Ott, 2017), concerns were on whether AI systems such as robotics have come to replace human workers (DeCanio, 2016), as the rise of AI and automation of work was seen to more generally contribute to economic inequality. DeCanio further opined that the introduction of new technology in carrying out work processes is bound to disrupt production and labour market, as some human skills will be rendered obsolete, while new skills will be required to complement the advanced technology, which Schumpeter (1950) referred to as creative destruction.

Further progress has been made since the turn of the century, research has shown that technological advancement can actually interact with human (labour) to increase employment in some sectors and occupation of work while decreasing it in other sectors and occupation (Acemoglu, 2002; Saint-Paul, 2008; Acemoglu \& Autor, 2011; Rodrik, 2016). Although, the main objective of AI was to substitute human lab our in order to achieve efficiency through labour cost savings, the focus today has shifted to more cooperation between humans and machines (Decker et al., 2017).

One crucial issue since the introduction of AI has been centered around loss of jobs, and substitution of human labour with machine (Decker et al., 2017) with concentration on the economic gains for organizations through cost reduction, increased profitability, reduced time wastage, competitiveness, production efficiency and meeting customers demand through new development of scientific and development tools (Dirican, 2015).

Employees all over the world have one time or the other rejected AI due to fear of loss of jobs with only minimal percentage of employees embracing it as complement to work processes, because most employers, managements, CEOs are of the opinion that machines help reduce labour cost and do not demand for wage increase, are able to work long hours, perform multiple tasks that most humans cannot possibly do (Qureshi \& Syed, 2014).

Adopting AI has not been an easy feat to accomplish, as less than $39 \%$ of all companies across the world have an AI strategy in place (Ranbotham, Kiron, Gerbert, \& Reeves, 2017). As more value creation job processes in the service sector become automated, existing skills requirements and job profiles come under pressure, and a large share of employment comes under high risk of computerization (Frey \& Osborne, 2013). As more and more organizations in Africa and indeed the rest of the world embrace globalization, advancement in technology and technical work processes, and AI systems, most employees that refuse to upgrade their knowledge, skill and attitude (KSA) fear of loss of jobs, redundancy, and retrenchment will eventually materialize (Elumelu, 2019).

Adoption of AI systems in Nigeria is possibly still at its very low, not just due to employee sabotage but because the needed environment to make it a success in every sector of the economy, vis-a-vis, improve power (electricity) supply, favourable technological environment through space satellite transmission, required training, updated educational curriculum that will have infused 
technological compliant course contents etc, have not been made available by the responsible stakeholders. These are the rationale behind this study.

\subsection{Objective of the Study}

The main objective of this study is to investigate Artificial intelligence and performance in the Nigerian Banking industry. This is with an intention to deduce if it is a challenge or a complement to work processes in the Nigerian Banking industry. In achieving this, the specific objectives are to:

1. Examine the complementability of Artificial Intelligence on work processes in banking operations in Nigeria;

2. Assess the ease of operations through machine-aided tasks of Banks in Nigeria.

\subsection{Research Questions}

The research questions developed to actualize the objective of this study are:

1. Does Artificial Intelligence complement work processes in banking operations in Nigeria?

2. Does machine-aided tasks ease banking operations in Nigerian banking industry?

\subsection{Hypotheses}

In achieving the above stated objectives of the study, the researcher intends to test the following hypotheses constructed in line with the study under consideration.

1. $\mathrm{H}_{0}$ : Artificial Intelligence does not complement work processes in banking operations in Nigeria;

2. $\mathrm{H}_{0}$ : Machine-aided task does not lead to ease of operations in Nigerian Banks.

\subsection{Literature Review}

Various concepts of AI and performance, theories that underpin this study, empirical findings of previous research works as it relates to the study of interest to the researchers are discussed below.

\subsection{Conceptual Clarification}

Artificial Intelligence connotes the ability to adapt effectively to environmental changes either by making changes to oneself or changing the environment through machine (Britannica, 2001). it entails the study of how to make computers do things in which at the moment humans are better (Rich \& Knight, 1991 cited in Nordlander, 2001). Due to the broadness of the concept of AI, it has been subdivided in Weak AI and Strong AI (Nordlander, 2001). Weak AI advocates argues that it involves adding some types of thinking features to computers to make them more useful for humans, while Strong AI proponents maintain that computers can be made to mimic the thinking process of the human brains, i.e, robotics (see Russell \& Norvig, 2001; Goodwins, 2001). Maney (2001) reported that AI helps manage workload by understanding what humans are doing, evaluating work, making decisions about what information and messages should be delivered at a given time. 
Artificial Intelligence is the ability of a computer programme or a machine to think and learn. It is also a field of study which tries to make computers smart. They work on their own without being encoded with commands. The first mention of AI was in 1955 by John McCarthy. Kaplan and Haenlein (2018) classified AI into three (3) types of AI systems, vis, Analytical AI which has characteristics consistent with cognitive representation of the world and using learning based on past experience to inform future decisions; Human-inspired AI which has elements from cognitive as well as emotional intelligence, understanding, as well as human emotions that are considered in their decision making process; and Humanized AI which shows characteristics of all types of competencies (cognitive, emotional and social intelligence) and are able to be self-conscious and self-aware in interactions with others. This can be achieved by observing AI through the lens of evolutionary stage (artificial narrow, artificial general intelligence, and artificial super intelligence) or by focusing on different types of AI systems (analytical AI, human-inspired AI, and humanized $\mathrm{AI})$.

The $21^{\text {st }}$ century has since experienced a resurgence in AI techniques following concurrent advances in computer power, large amount of data, and have become an essential part of the technology industry, helping to solve many challenging problems in computer science, software engineering and operational research (Dudhe \& Rane, 2017). AI is not some magic wielding computerized character, it involves a wide range of algorithms (that are fast and can analyze millions of information in seconds) and machine learning tools that can rapidly inject data, identify patterns, optimize and predict trends (Ahmed, 2018). The system has the ability to understand speech, identify photos, use pattern matching to pick up signals that are necessary (Ahmed, ibid). Statistically, AI systems can predict and learn by plotting curves of possible outcomes and then optimizing decisions based on many criteria.

\subsection{Performance}

Performance can be defined as the achieved desired results. It is the ability of an organization to fulfill its mission, vision and corporate objectives through sound management, strong governance and a relentless re-dedication to achieving results (Mahapatro, 2010). Organizational performance is used to measure the effectiveness and efficiency of an organization, it involves the recurring activities to establish organizational goals, monitor progress towards these goals, and make adjustments to achieve these goals more effectively and efficiently (Ratna, Khanna, Jogishwar, Khattar \& Agarwal, 2014).

In measuring performance of banks the parameters listed below as tools of Artificial Intelligence and its application will be discussed briefly by the researchers.

\subsubsection{Tools used by AI}

Large number of tools have been developed by AI to solve the most difficult of problems associated with the computer age (Dudhe \& Rane, 2017), among which are:

i. Search and optimization tool: Most problems in AI have their solution in theory by searching through pools of solutions intelligently, such as planning algorithms which searches through trees of goals and sub-goals, attempting to find a path to a target goal. 
ii. Logic: This is used for knowledge representation and problem solving. Several forms of logic are used in AI research such as proportional logic, first-order logic, fuzzy set theory logic, etc.

iii. Probabilistic methods for uncertain reasoning: AI problems such as reasoning, planning, learning, perception and robotics requires operations with incomplete information and these can be solved using tools with problem solving methods from probability theory and economic tools.

iv. Classifiers and statistical learning methods: Classifiers are functions that use pattern matching to determine a closest match. They can be tuned according to examples making them very attractive for use known as observations or patterns. Classification form a major part of many AI systems. Controllers, on the other hand infer actions.

v. Artificial neutral networks: Neutral networks which were inspired based on neurons in the human brain accepts input from multiple other neurons, each of which when activated, cast a weighted "vote" for or against whether such neurons should be activated. Neutral networks can learn both continuous and digital logical operations.

vi. Evaluating progress: AI is a general purpose technology. There is no consensus on how to characterize which task AI tends to excel in.

\subsubsection{AI Applications}

Today, Artificial Intelligence is relevant to many task, from autonomous vehicles such as drones, self-driving cars to medical diagnostic robotics, creating art, proving mathematical theorems, playing games such as cheese, search engines such as google search, online assistants such as Siri, image recognition in photography, predicting flight delays, prediction of judicial decisions, online marketing tools such as Ali-Baba, and Jumai, Video Assistant Referee (VAR) recently introduced into field sports to aid refereeing decisions among others. Organizational sectors have not been left out from Healthcare to automobiles, finance and economics, marketing, including research and education where students receive online interface lectures.

\subsubsection{Benefits of Artificial Intelligence}

The benefits of AI in today's world and indeed the business environment are numerous, below are a list of the few benefits associated with AI systems:

i. New technologies forces people in an organization to improve their cognitive literacy (Holtel, 2016).

ii. Reduction in cost of operations.

iii. Reduction in man-hour wastage (time wastage).

iv. Access to large pools of customers, suppliers, distributors, modern techniques, markets etc (Ransbotham et al., 2017).

\subsection{Artificial Intelligence in the Banking Sector in Nigeria}

The bank which a a key financial player in any economy has experienced drastic change from the days of manual operations (papers, cheque-books, etc) to modern era of automated teller machines 
(ATM), online banking, internet operations, mobile banking, process operations, to mention a few, thanks to globalization and continuous technological advancement. As business expectation increases, finance functions have gone beyond meeting the traditional operational finance objectives and maintaining the company's bottom-line, there is constant pressure to provide strategic direction to the business to help make better informed decisions (Liadi, 2019). Liadi, also noted in his paper "the future of finance-technology at play" that finance functions in modern times are strategic, analytical, data-driven powerhouses that encompasses digitization and drives performance, hence adding value to business. He argued that a combination of an efficient finance model, technologies, and highly skilled people is what is needed to successfully adapt AI systems to finance functions of the future.

Deloitte report of 2016 on "Finance in a digital world" identified seven (7) technologies that modern finance functions requires. These technological tools where further categorized as either "core modernization tools" or "exponential tools" in the report.

2.3.1 Core modernization tools: these tools focus specifically on updating financial systems and existing capabilities. Tools such as clouds, process robotics and visualization were categorized here.

a. Cloud: a cloud is a colony of millions of computers that are braided together seamlessly to act as a single large computer, companies like Uber, AirBnB uses cloud operations, it does not require costly updates and maintenance.

b. Process robotics: cost reduction and improved efficiency are the gains of automated processes and repetitive manual tasks through these technological solutions.

c. Visualization: this helps technology to turn increasing amounts of raw data into accessible insights for an organization. Traditional spreadsheet metrics turned into pictures and infographics make important organizational stories easier to understand for non-finance functions. Moreover, these tools help speed up processes when using data and exploring for prototyping and scenario planning.

2.3.2 Exponential tools: exponential tools focuses on delivering new capabilities to the finance functions. Tools such advanced analytics, cognitive computing, in-memory computing and block chain were identified under this category.

a. Advanced analytics: these tools can greatly improve the effectiveness of planning and forecasting leading to deeper business insights and better predictive modelling. It also helps to erase the boundaries between the world of data scientist and that management accountant.

b. Cognitive computing: this encompasses fields such as AI, speech recognition and machine learning. They work together to provide automated insights into the increasing amounts of data finance professionals have access to.

c. In-memory computing: this involves technical architecture storage solutions, where information sits in dedicated Random Access Memory (RAM) servers, with faster data transfer rates within RAM, the ability to handle and interrogate massive live data sets quickly and more efficiently is enhanced. 
d. Block chain: this is a digital platform that stores records of value transactions through a distributed, peer-to-peer networks. The records on a block chain are immutable, which means the ledger is verifiable and auditable, examples are bitcoin currency.

Together, Deloitte's research suggests that the seven (7) technologies are helping organizations in improving performance and making the finance function serve customers more effectively. Elumelu (2019) in agreeing with Liadi opined that for today's finance professionals including bank employees to continue to be relevant, there must be a mastery of the necessary technical skills and pragmatic demonstration of high levels of business acumen, leadership and communication skills with AI systems, as technological impact on finance functions continues to grow drastically by the day. Data mining, extraction, faster interpretation of big data, statistical modelling, and data analysis, financial analysis and planning, budgeting, forecasting and operational analysis are skills set that finance professionals of today need to hone to stay relevant.

\subsubsection{Barriers to Adopting AI in Nigerian Business Environment}

Certain barriers have been identified as hindrance to the smooth adoption and operations of AI systems in developing countries like Nigeria and worst still third world countries, albeit with certain sectors in these countries having adopted as experimenters or passive adopters, but in Nigeria, sectors like the telecommunication sector, the banking sectors are pioneers and early adopters of AI systems having started operations in their operations. This is yet visible in other sectors in these countries. The underlisted barriers have been identified:

i. Human resistance owing to fear of loss of job or redundancy on the job.

ii. Artificial intelligence compliant cognitive and mental skills needed to effectively operate AI systems, machines, computers and robotics.

iii. Macro environment forces such as economic instability, political interference, corruption in high places, infrastructural deficiencies such as inadequate power supply to operate these systems, lack of government support.

iv. Institutional deficiencies such as inadequate educational foundations, un-updated curriculum of learning to include AI learning tools.

v. The problem of grappling with practicalities of developing or acquiring the requisite AI talents and addressing competing priorities for AI investments faced by managers and business owners.

vi. Workplace implications which stems from integrating the capabilities of human and machines collaborations. Since people cannot be entirely removed from the process, the problem of effective coordination of work and/or effective communication between man and machine has not been effectively tackled today and still remains unsolved (Ransbotham et al., 2017).

\subsection{Theoretical Framework}

For the purpose of this study, two (2) relevant theories will be discussed, which forms the foundation of Artificial Intelligence. The first being the Technology Acceptance Theory which was developed by Davis in 1986, was aimed at explaining the behavioural intentions of users to accepting and usage of new technologies and innovation. Technological innovations are often 
perceived as threats to an existing model or mode of performing tasks or carrying out actions but in reality embody opportunities for enhanced and improved service delivery. The struggle as identified by researchers was to overcome barriers to acceptance of new innovations (Okoye, Omankhanlen, Okoh, Ezeji \& Achugamonu, 2019). These barriers may be in form of reluctance of employees to migrate from known and predictable to unknown and unpredictable platforms and these, more often than none determines the adoption or acceptance rate of new technological innovations (Lai, 2017). The theory of Technological Acceptance Model (TAM) has its root from the Theory of Reasoned Action (TRA) which was developed by Fishbein and Ajzen in 1975 which aims to explain the relationship between attitudes and behaviours in human actions. It states that a person's intention to perform a behaviour is the main predictor of whether or not they actually performed that behaviour. This theory is also used in communication discourse as a theory of understanding. The theory requires that behaviour be clearly defined in terms of the following: $i$. Action; ii. Target; iii. Context; and iv. Time.

According the Davis as cited in Okoye et al, (2019) the perceived usefulness of an innovation refers to the probability that the usage of a new application, appliance, programme will enhance performance, while the perceived ease of usage refers to the ability of the users (in this case bank operators) to engage the said application, appliance, and/or programme with minimal or no effort, which is aimed at adding value and thereby enhancing user satisfaction. Surendran (2012) identified political factors and social factors as two major external factors that affect system predictors (perceived usefulness and perceived ease of usage) as shown in the fig. 1 below.

\subsection{Empirical Review}

AI systems have had tremendous impact of banking operations with drastic changes to work processes, customer relationship, data gathering, storage, analysis and interpretation and researchers have been keen to study its impact and effect on banking operations across the world. These studies and their outcomes will be discussed briefly.

Haque (2013) in his study of alternative banking channels found that the growth of digital banking platforms are due to cost-effectiveness and convenience gotten from investing in technologies and innovations that enables bank operators to reach customers through alternative channels such as ATMs, online portals, mobile applications etc, this finding was similar to that of Kaur and Kiran (2014) where they found that bank customers had a preference for electronic banking platforms due to their convenience.

Kwarteng (2015) explored the relationship between electronic banking and customers service delivery in Kumasi, Ghana taking a sample of 69 bank customers and 29 staffs from three branches of deposit money banks (DMBs) using purportive sampling techniques. His study revealed branch banking as customers preferred channel of delivery in-spite of the high level of awareness of ebanking services and the long queues associated with branch banking, but when digital banking was an option ATM channel was the preferred choice.

Agboola (2003) in his study of the link between e-banking and quality of service delivery by technology-compliant DMBs took a sample of 90 customers from six (6) different banks within 
Lagos metropolis and found that the introduction of e-banking produced drastic changes in both the service delivery techniques and the range of products offered.

Uppal (2011) while analysing the growth of infotech in various banking groups in India, studied public and private sector banks and also foreign banks in India and the study revealed that private sector banks and foreign banks have deployed IT applications for effective service delivery while the public sector banks still engage in brick and mortar banking operations. His conclusion was that for firms to survive in an era of intense competition its capacity to acquire and deploy the requisite technological infrastructure will be key.

Choudhury and Bharttachargee (2016) examined the relationship between banking channels and customer loyalty while using a survey method to sample 400 employees selected through stratified sampling method. Their study was measured based on ease of use of e-banking service delivery channels, its usefulness, cost-savings, and self-control, while loyalty was measured in terms of attitudinal loyalty and behavioural loyalty. Their study revealed that electronoc banking had strong positive impact on customer loyalty.

Oluwagbemi, Abah and Achimugu (2011) examined how adoption of information technology impacted the banking industry in Nigeria. Their findings revealed that IT adoption fundamentally transformed the content and quality of banking service delivery thereby strengthening the competitiveness of Nigerian banks.

Jeong and Yoon (2013) examined major influencers of mobile banking adoption using a sample of 165 respondents in Korea. They observed that quality of mobile banking services which was measured by its perceived usefulness, ease of use, credibility, and self-efficacy has strong impact on customers' disposition to mobile banking adoption. Similarly, Ho and Ko (2008) also found strong positive effect of self-service technology characteristics like ease of usage, usefulness, costsavings and self-control on customers' continued use of internet banking facilities. They observed that these attributes creates value for customers and thereby enhances their readiness to engage self-service delivery channels for their transactions.

Akanbi, Ayodele and Adedipe (2014) studied factors that influences customer's retention to use internet banking among students of a private university in Nigeria with sample size of 357 respondents purposively selected from three (3) Faculties of the institution of learning. Their findings revealed the perceived ease of use, capability, perceived usefulness, triability, and compatibility as influencers of internet banking adoption among students.

\subsection{Research Methods}

This study was structured to study Artificial Intelligence and performance in the Nigerian banking industry. It was designed to investigate how AI has impacted on banking operations from an employees' perspective, its complementability on work processes, and ease of operations through machine-aided tasks. Cross sectional survey method was adopted by the researchers for this study, questionnaires was designed to generate data from respondents following a 5-point Likert scale rating. Six (6) banks operating within the Lagos State University, Ojo, Lagos State, Nigeria were used as study with sample size of 98 drawn from the employees of these banks. 98 number of 
questionnaires were returned out of which 98 number amounting to $100 \%$ was in usable form to analyze data.

Reliability test was conducted using Cronbach Alpha to ensure internal consistency and stability of the measuring instruments used by the researcher and it returned a Cronbach Alpha coefficient of 0.773 as shown below, which is acceptable reliability and is an indication that the test result was consistent over time. Regression analysis was used to analyze data while sample percentage and mean was used for demographic analysis of respondents.

Reliability Statistics

\begin{tabular}{|c|c|}
\hline $\begin{array}{c}\text { Cronbach's } \\
\text { Alpha }\end{array}$ & No of Items \\
\hline .773 & 10 \\
\hline
\end{tabular}

\subsection{Data Presentation and Analysis}

Table 1: Demographic Analysis of Respondents

\begin{tabular}{|c|c|c|c|c|}
\hline & Frequency & Percent & Valid Percent & Cumulative Percent \\
\hline Sex & & & & \\
M & 43 & 43.9 & 43.9 & 43.9 \\
F & 55 & 56.1 & 56.1 & 100.0 \\
\hline Age & & & & \\
$21-30$ & 28 & 28.6 & 28.6 & 65.6 \\
$31-40$ & 36 & 36.7 & 36.7 & 89.8 \\
$41-50$ & 24 & 24.5 & 24.5 & 100.0 \\
51-above & 10 & 10.2 & 10.2 & 59.2 \\
Qualification & & & & 83.7 \\
BSc/BA & 58 & 59.2 & 59.2 & 100.0 \\
MSc/MBA/MA & 24 & 24.5 & 24.5 & 53.1 \\
Others & 16 & 16.3 & 16.3 & 87.8 \\
\hline Position & & & & 100.0 \\
Junior Staff & 52 & 53.1 & 53.1 & 100.0 \\
Senior Staff & 34 & 34.7 & 34.7 & 12.2 \\
Management Staff & 12 & 12.2 & 100 & \\
\hline Valid Total & 98 & 100 & & \\
\hline
\end{tabular}

Source: Field Survey, 2019

\section{Respondents Demographic Attributes}

From the spread of the sample size based on sex distribution of respondents, 43 respondents representing $43.9 \%$ of respondents are male, while 55 respondents representing $56.1 \%$ are female. This is as a result of more females working in the banking industry. Age distribution revealed 28 
respondents representing $28.6 \%$ between the ages $21-30$ years, 36 respondents representing $36.7 \%$ between the ages of 31-40 years, 24 respondents representing 24.5\% between the ages of 41-50 years while 10 respondents representing $10.2 \%$ between the ages 51 years and above, this shows that most employees in the banking industry are middle age adults. On the Qualification in terms of education, the distribution shows that 58 respondents representing $59.2 \%$ had BSc/BA, 24 respondents representing $24.5 \%$ had $\mathrm{MSc} / \mathrm{MBA} / \mathrm{MA}$ and 16 respondents representing $16.3 \%$ had other qualification, this shows that most employees of the banking industry in Nigeria had a minimum qualification of BSc/BA. The Position occupied in the bank shows a distribution of 52 respondents representing $53.1 \%$ being junior staffs of the banks, 34 respondents representing $34.7 \%$ being senior staffs and 12 respondents representing $12.2 \%$ were on management staffs cadre, this findings revealed that most employees of the banking industry in Nigeria were at junior staffs of their respective banks. The contribution of the banks in Lagos State University, Lagos, Nigeria under study are broken down below.

Table 2: Contributions to Population of the Study

\begin{tabular}{|l|c|c|c|c|c|c|}
\hline BANKS/CONTRIBUTION & UBA & WEMA & ACCESS & UNION & ZENITH & STERLING \\
\hline Population of study & 18 & 17 & 22 & 28 & 23 & 19 \\
\hline Sample size & 11 & 14 & 21 & 24 & 15 & 13 \\
\hline Respondents (returned) & 11 & 14 & 21 & 24 & 15 & 13 \\
\hline Respondents (analyzed) & 11 & 14 & 21 & 24 & 15 & 13 \\
\hline $\begin{array}{l}\text { TOTAL Population/Sample } \\
\text { Size/Returned/Analyzed }\end{array}$ & \multicolumn{7}{|l}{ 127 Elements/98 Respondents/98 returned/98 valid and usable } \\
\hline
\end{tabular}

Source: field survey, 2019

\subsection{Data Analysis}

\subsubsection{Hypotheses Testing}

\section{Hypothesis 1}

$\mathrm{H}_{0}$ : Artificial Intelligence does not complement work processes in banking operations in Nigeria

Model Summary ${ }^{b}$

\begin{tabular}{|l|r|r|r|r|r|}
\hline Model & \multicolumn{1}{|c|}{$\mathrm{R}$} & R Square & $\begin{array}{c}\text { Adjusted R } \\
\text { Square }\end{array}$ & $\begin{array}{c}\text { Std. Error of the } \\
\text { Estimate }\end{array}$ & Durbin-Watson \\
\hline 1 & .513 & .263 & .256 & .50389 & 1.948 \\
\hline
\end{tabular}

a. Predictors: (Constant), Artificial Intelligence 
b. Dependent Variable: Employee Performance

The model summary table above shows the contribution of the predictor Artificial intelligence to the dependent variable Employee performance. The $\mathrm{R}^{2}$ value of $0.263(26.3 \%)$ indicates the percentage of variation in the dependent variable Employee performance that can be explained by the constant Artificial intelligence.

ANOVA $^{\mathrm{a}}$

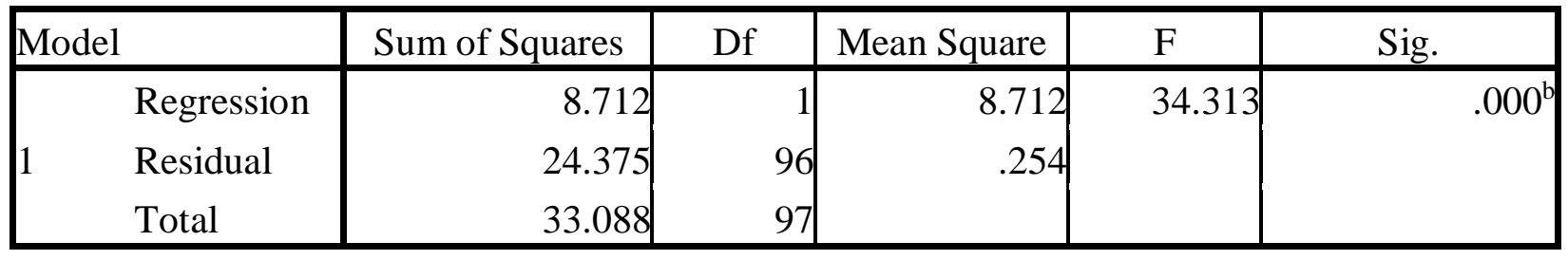

a. Dependent Variable: Employee Performance

b. Predictors: (Constant), Artificial Intelligence

The Anova table above shows the assessment of the regression model which predicts the dependents variables significance. This test the null hypothesis to determine its statistical significance, the $\mathrm{F}$ value and $\mathrm{P}$ value is used to determine this. The result of the model in the table above indicates that the regression model statistically significantly predicts the outcome since the $\mathrm{p}$ value of $0.000<0.05$ and the $\mathrm{F}_{\text {observed }} 34.313>\mathrm{F}_{\text {critical }} 3.09$ the null hypothesis is therefore rejected.

\section{Coefficient}

\begin{tabular}{|ll|l|l|l|l|l|}
\hline \multirow{2}{*}{ Model } & \multicolumn{2}{|l|}{$\begin{array}{l}\text { Unstandardized } \\
\text { Coefficients }\end{array}$} & $\begin{array}{l}\text { Standardized } \\
\text { Coefficients }\end{array}$ & T & \multirow{2}{*}{ Sig. } \\
\cline { 2 - 5 } & & B & Std. Error & Beta & & \\
\hline \multirow{2}{*}{1} & (Constant) & 1.335 & .503 & & 2.656 & .009 \\
& Artificial Intelligence & .663 & .113 & .513 & 5.858 & .000 \\
\hline
\end{tabular}

a. Dependent Variable: Employee Performance

The coefficient table above shows the contribution of the variables to the dependent variable. The study undertakes to compare the contribution of the independent variable Artificial Intelligence using the beta coefficient value 0.663 in the unstandardized coefficient. This means that changes in Artificial Intelligence contributes to complementing Employee Performance in Nigeria Banking Industry operations. 


\section{Hypothesis 2}

$\mathrm{H}_{0}$ : Machine-aided task does not lead to ease of operations in Nigerian Banks.

\begin{tabular}{|l|l|r|r|}
\hline \multicolumn{2}{|l|}{ Correlations } & \multicolumn{1}{c|}{$\begin{array}{c}\text { Artificial } \\
\text { Intelligence }\end{array}$} & $\begin{array}{c}\text { Employee } \\
\text { Performance }\end{array}$ \\
\hline \multirow{3}{*}{ Artificial Intelligence } & Pearson Correlation & 1.000 & $.591^{* * *}$ \\
\cline { 2 - 5 } & Sig. (2-tailed) & .000 \\
\cline { 2 - 5 } & $\mathrm{N}$ & $.591^{* *}$ & 98 \\
\hline \multirow{3}{*}{ Employee Performance } & Pearson Correlation & .000 & 1.000 \\
\cline { 2 - 5 } & Sig. (2-tailed) & 98 & 98 \\
\cline { 2 - 5 } & $\mathrm{N}$ & & \\
\hline \multirow{2}{*}{$* *$ Correlation is significant at the 0.01 level (2-tailed). }
\end{tabular}

The result of the correlation for hypothesis 2 tested above by the researcher reveals that there is a perfect positive relationship between machine-aided task and the ease of operations of bank employees in carrying out their job and routine task in the banks in the Lagos State University, Ojo, Nigeria as obtained by the Pearson correlation of 0.591. The Significant 2-tailed test result shows that $0.000<0.05$ which is the study's standard alpha value. This shows that the study highly significantly predicts that Machine-aided task does lead to ease of operations in the banking industry in Nigeria.

\subsection{Discussion of Findings}

Hypothesis 1 which tested to the null hypothesis Artificial Intelligence does not complement work processes in banking operations in Nigeria was carried out using regression analytical tool. The result obtained revealed that the independent variable Artificial Intelligence contributes $26.3 \%$ to the variation of the dependent variable Employee Performance. The findings also showed that the study is statistically significant because of the $\mathrm{p}$ value of $.000<0.05$ and an $\mathrm{F}_{\text {observed }} 34.313>\mathrm{F}_{\text {critical }} 3.09$ which was enough to reject the null hypothesis and submit that Artificial Intelligence actually complement work processes in banking operations in Nigeria. This finding is synonymous with the findings of Choudhury and Bharttachargee (2016), who examined the relationship between banking channels and customer loyalty while using a survey method to sample 400 employees selected through stratified sampling method. Their study was measured based on ease of use of e-banking service delivery channels, its usefulness, cost-savings, and selfcontrol, while loyalty was measured in terms of attitudinal loyalty and behavioural loyalty. Their study revealed that electronic banking had strong positive impact on customer loyalty.

Hypothesis 2 which test the null hypothesis Machine-aided task does not lead to ease of operation in Nigerian Banks was conducted using Pearson Product Moment Correlation Coefficient. The result obtained revealed a perfect positive correlation between machine-aided task and ease of operations in Nigerian Banking Industry as revealed by the findings associated with the scope 
which are banks operating within the Lagos State University, Lagos, Nigeria. The findings also showed that the study is significant with the significant 2 -tailed of $0.000<0.05$ the standard alpha value of the study. This findings is consistent with the findings of Oluwagbemi, Abah and Achimugu (2011) when they examined how adoption of information technology impacted the banking industry in Nigeria and their findings revealed that IT adoption fundamentally transformed the content and quality of banking service delivery thereby strengthening the competitiveness of Nigerian banks.

\subsection{Recommendations}

The study recommends the following:

i. The adoption of Artificial Intelligence must become part and parcels of not just banking operations but all organizations that must enjoy smooth, reliable, effective, efficient and up-to-date operations in Nigeria.

ii. Employees must be educated on the need to embrace Artificial intelligence as a complement to work and not a treat to their survival on the job.

iii. The need for all to evolve to the era of Artificial Intelligence cannot be over-emphasized as the effect of globalization and technological advancement has taking over today's world.

iv. School curriculum must be upgraded to incorporate Artificial intelligence and its accompanying gadgets so that kids get grounded on the applications and usage of machines and robotics.

\subsection{Suggestion for Further Studies}

Because of limitations faced by the researchers this study could not incorporate robotics and their effects on manufacturing industry in developing economy like Nigeria. This is a grey area and further studies could be expanded in this area.

\section{References}

Acemoglu, D. (2002). Technical change, inequality, and the labour market. Journal of Economic Literature, 40, 7-72.

Acemoglu, D., \& Autor, D. (2011). Skills, tasks and technologies: Implications for employment and earnings.In: Ashenfelter, Orley, Card, David (Eds.). Handbook of Labor Economics, San Diego: North Holland, Vol. 4B.

Agboola, A.A. (2003). Impact of electronic banking on customer services in Lagos, Nigeria. Journal of Social Sciences, 7(1), 27-36.

Ahmed, O. (2018). Artificial Intelligence in HR. International Journal of Research and Analytical Reviews, 5(4), 971-978. 
Akanbi, P.A., Ayodele, T.D., \& Adedipe, O.A. (2014). An investigation in some factors influencing the intention to use internet banking among undergraduates in Nigeria. Research of Finance and Accounting, 5(8), 1-10.

Choudhury, D., \& Bhattachargee, d. (2016). Role of e-banking delivery channel in developing loyalty: a study of salaried employees. Hind Business Review, 2(2), 65-72.

DeCanio, S. (2016). Robots and human-complements or substitutes? Journal of Macroeconomics, 49, 280-291.

Decker, M., Fischer, M. \& Ott, I. (2017). Service robotics and human labor: A first technology assessment of substitution and cooperation. Robotics and Autonomous Systems, 87, 348-354.

Dirican, C. (2015). The impacts of robotics, artificial intelligence on business and economics. Procedia Social and Behavioural Sciences, 195, 564-573.

Dudhe M., \& Rane, D. (2017). Technical support and implementation of AI. OOSR Journal of Engineering, 84-89.

Elumelu, T.O. (2019). The Future of Finance-Technology at play. Conference paper delivered at Lagos State University, Faculty of Management Sciences, 2019 Annual Public Lecture.

Fishbein,M., \& Ajzen, I. (1975). Belief, Attitude, intention and Behaviour: An Introduction to Theory and Research. Addison-Wesley Publishing Company, Reading, Mass; Don Mills, Ontario.

Frey, C.B., \& Osborne, M.A. (2013). The future of employment: How susceptible are jobs to computerization? Oxford University Engineering Sciences Department and Oxford Martin Programme on the Impacts of Future Technology, Workshop on "Machines and Employment."

Goodwins, R. (2001). The machine that wanted to be a mind. ZDNet news portal. Available from: http://news.zdnet.co.uk/story/0,s2083911,00.html. (Accessed 24 June, 2019).

Haque, S.Z. (2013). Alternate channels of banking, Internship Report, BRAC Univ. Bus. Sch. http://dspace.bracu.au.bd:8080/xmlui/bitstream/handle/10361/2867/09204002.pdf?sequence=1. Accessed on $21^{\text {st }}$ June, 2019.

Ho, S-H., \& Ko, Y-Y. (2008). Effects of self-service technology on customer value and customer readiness: The case of internet banking. Internet Research, 18(4), 427-446.

Holtel, S. (2016). Artificial Intelligence creates a wicked problem for enterprise. Procedia Computer Science, 99, 171-180.

Jeong, B-K., \& Yoon, T.E. (2013). An empirical investigation of customer acceptance of mobile banking services. Business and Management Research, 2(1), 31-40.

Kaplan, A. \& Haenlein, M. (2018). Siri, Siri in my hand, who's the fairest in the land? On the interpretations, illustration and implications of Artificial Intelligence. Business Horizon, 62(1). Jump up to a-b. Optimum of early AI. 
Kaur, N., \& Kiran, R. (2014). E-delivery channels and banking performance in India: A pragmatic approach. Global Journal of Management and Business Research-C Finance, 14(4), 11-21.

Kwarteng, P.A. (2015). The effect of electronic banking on customer service delivery in Kumasi Metropolis. Unpublished Thesis, Kwame Nkrumah University of Science and Technology. Accessed $21^{\text {st }} 2019$. http://ir.knust.edu.gh/bitstream/123456789/8585/1/PRINCE\%20ADIYIA\%20KWARTENG.pdf.

Lai, P.C. (2017). The literature review of technology adoption models and theories for novelty technology. Journal of Information System and Technology Management, 14(1), 21-38.

Liadi, A. (2019). The Future of Finance-Technology at play. Conference paper delivered at Lagos State University, Faculty of Management Sciences, 2019 Annual Public Lecture.

Mahapatro, B.B. (2010). Human Resources Development. In Mahapatro, B.B., Human Resources Management (272-289). New Delhi, ND, New Age International (P) Ltd.

Maney, K. (2001). Artificial Intelligence isn't just a movie. USA Today. Available from: http://www.usatoday.com/news/acovwed.htm. (Accessed 24 June, 2019).

Nordlander, T.E. (2001). AI surveying: Artificial Intelligence in business. A thesis submitted to department of Management Science and Statistics, De Montfort University.

Okoye. L.U., Omankhanlen, A.E., Okoh, J.I., Ezeji, F.N. \& Achugamonu, U.B. (2019). Imperatives for deepening customer service delivery in Nigerian Banking Sector through engineering and technology-based channels. International Journal of Civil Engineering and Technology, 10(1), 2156-2169.

Oluwagbemi, O., Abah, J., \& Achimugu, P. (2011). The impact of information and communication technology in banking industry. Journal of Computer Science and Engineering, 7(2), 63-67.

Qureshi, M.O., \& Syed, R.S. (2014). The impact of robotics on employment and motivation of employees in the service sector, with special reference to health care. Safety and Health at Work, 5, 198-202.

Ransbotham, S., Kiron, D., Gerbert, P., \& Reeves, M. (2017). Reshaping business with Artificial Intelligence. MIT Sloan Management Review and the Boston Consulting Group.

Ratna, R., Khanna, K., Jogishwar, N., Khattar, R., \& Agarwal, R. (2014). Impact of learning organizations on organizational performance in consulting industry. International Journal on Global Business Management and Research, 3(2). ISSN 22788425.

Rodrik, D. (2016). Premature deindustrialization. Journal of Economic Growth, 21(1), 1-33.

Russell, S. \& Norvig, P. (2001) FAQ's for AI (WWW). Available from: http://www.doi.ic.ac.uk/project/2001/firstyeartopics/g01t28/faqs.html (Accessed 24 June, 2019). 
IJMA

Saint-Paul, G. (2008). Innovation and inequality: How does technical progress affect workers. Princeton University Press, Princeton.

Schumpeter, J.A. (1950). Capitalism, socialism and democracy. Third Edition Harper Torchbooks, New York.

Surendran, P. (2012). Technology acceptance model: A survey of literature. International Journal of Business and Social Research. 2(4), 175-178.

Uppal, R.K. (2011). E-delivery channels in banks: A fresh outlook. Researchers World-Journal of Arts Science and Commerce, 11(1), 178-188. 